\title{
Functional and Harmonious Self-organization of Large Intellectual Agent Ensembles with Smart Hybrid Competencies
}

\author{
Evgeny Bryndin \\ Research Department, Research Center «Natural Informatics», Novosibirsk, Russia
}

Email address:

bryndin15@yandex.ru

\section{To cite this article:}

Evgeny Bryndin. Functional and Harmonious Self-organization of Large Intellectual Agent Ensembles with Smart Hybrid Competencies. American Journal of Artificial Intelligence. Vol. 10, No. 1, 2021, pp. 1-10. doi: 10.11648/j.ajsea.20211001.11

Received: April 20, 2021; Accepted: June 5, 2021; Published: May 14, 2021

\begin{abstract}
Artificial intelligence of large ensembles of intelligent agents in terms of computing power surpasses human intelligence. He is capable of artificial thinking and understanding. Giant ensembles of intellectual agents with artificial consciousness and intelligence are able, for the results set by the person necessary for him, to find solutions for their obtaining on the basis of professional competence and experience accumulation. The professional competence of artificial intelligence is the ability to use technologies, including computer vision, natural language processing, speech recognition and synthesis, intelligent decision support, as well as the use of synergistic methods, functional self-organizing methods and utility and preference criteria. For artificial intelligence, the functional organization of the system is important. The functionalism of artificial intelligence does not depend on its carrier, allows many methods of its functional implementation, as well as to form the completeness of its functions. Giant ensembles of intellectual agents with a full set of functions gradually and flexibly form events into solutions or rational behavior to obtain a given necessary result. Intelligent artificial intelligence has psychological, analytical, research, language, professional and behavioral hybrid competencies. Each competence is exercised by an intelligent agent with a competent functional professional manner. Intelligent agents form an ensemble with intelligent ethical artificial intelligence. Functional harmonious self-organization of the interaction of intellectual agents in different environments is carried out on the basis of data of a specific environment obtained by analytical competent intellectual agents. For each set of functions and smart hybrid competencies of an intelligent ensemble, there is a critical importance for the number of its intellectual agents capable of synergistic self-organization of interaction.
\end{abstract}

Keywords: Intellectual Agent Ensembles, Smart Hybrid Competencies, Functional Harmonious Self-organization

\section{Introduction}

Inform-Systems has developed a technology for creating self-organizing IT-systems, which can be used to develop ERP, MES, SCADA systems. Self-organization brings new quality to the system. For example, as a result of selforganization, Smart-MES can calculate 1000 tasks with 500,000 indicators in just 10 seconds. The same number of tasks without self-organization will be calculated about two hours, i.e. somewhere 500 times longer. The Smart-MES self-organizing system represents the self-organizing of the second degree. But it is possible to create self-organization of the third degree, this is when the multi-agent system consists of self-organizing systems of the second degree. Here, the first degree produces self-tuning and adaptability, the second degree provides calculation speed, the third - allows the independent functioning of the system. The self-organization of Smart-MES is the beginning of the process of emergence of qualitatively new and more complex structures in the development of the system.

Smart-MES is a production management system that connects all business processes with the production processes of the enterprise, quickly providing objective and detailed information to the company's management. The Smart-MES construction methodology is focused on the easy implementation of any algorithms in any number without programmers. It contains a complete set of modern capabilities. These are text projects of technological tasks, 
and self-configuration of the entire system, and selforganization according to the current context, and analytics, and graphics, and optimization. And all this is possible in any client-server configuration. The Smart-MES system is not initially focused on solving any specific problems, but it contains in the form of an EXE module all the prerequisites for future specific implementation. The EXE module acquires the ability to solve specific problems by learning in a few seconds. The EXE module includes configuration tools and functionality based on the results of this configuration. Customization takes place during the conversion of text projects of tasks, the structure of which is very simple and consists of the description of columns and rows of the table. One table corresponds to one task with a set of calculation algorithms with a screen form and report.

When compiling projects, all databases, screen forms, calculation DLL programs, reports are automatically created. In order for the system to be adapted and able to function, nothing more is needed besides the EXE module and text projects. If a change or addition is required during the operation of the system, the text project is adjusted and compilation is started on the operating system. In this case, all changes will take place without losing the current technological information. A special advantage of this technology is that it provides absolute software reliability with any number of implemented technological calculation algorithms for any production.

The system conditionally consists of a basis and an add-on. A basis is an executive EXE module that does not have a process filling. An add-in is a text project of technological tasks. The basis is always unchanged, because it is the prerogative of the developer. The superstructure is subject to constant changes and is the prerogative of technologists to develop production tasks. Text projects of technological tasks determine the scope of their use and ensure the real functioning of the EXE module.

The technology of creating self-organizing IT systems includes five stages:

1) translation of task setting into the meta-language of the technologist;

2) conversion of meta-language to macro-language (selfconfiguration);

3) transformation of all tasks in macro language into one task (self-organization);

4) conversion of a single task into a programming language;

5) converting the programming language to the resulting machine code.

Ignoring any of the listed steps will not produce the desired result of self-organization of the system with the ability to adapt for a particular production and high calculation speed.

If individual self-organizing systems are presented as agents with mutual relations under special protocols, then a self-organizing multi-agent system will be obtained.

The Smart-MES system in the initial state does not have a single real-world task, does not have a database, does not have screen forms, does not have reports, does not have a single implemented algorithm for the technological task, and after compiling the text in the engineering language, everything appears. This is the operation of the text-tosystem conversion algorithm. The extremes of the goal of Smart-MES self-organization are minimizing the actions of the technologist when adapting the system to specific production conditions and maximizing the calculation speed of technological algorithms. Minimizing the actions of the technologist is ensured by the built-in tool "Project Designer" of technological tasks in text form. Each task in the engineering language is formulated in a tabular form, with which a person interacts. Separately, the contents of the columns of the table and its row are described. All algorithms are constructed from templates. The designation of indicators has the usual spelling for technologists with upper and lower indices. Maximizing the calculation speed is provided by four times converting the setting of the task into an executive machine code.

The main ridge skeleton of the system remains unchanged. If you briefly describe its capabilities, then the selforganization of the system is reduced to self-configuration. For this reason, the term "self-organizing system" is introduced, especially since with a superficial comparison with the paradigm of self-organization, there is little in common.

The main goal of any self-organization is to achieve constructive extremes of any aspects. After all, it is as a result of self-organization that everything develops. Selforganisation and communication in groups of simulated and physical robots [1]. Optimisation in self-modelling complex adaptive systems [2]. Importing complex systems and selforganization into engineering [3]. Information and selforganization [4]. Evolutionary game theory using agentbased methods [5]. Modeling collective rule at ancient teotihuacan as a complex adaptive system [6]. Guiding the self-organization of cyber-physical systems [7].

The article considers the approach to creating large selforganizing ensembles of intelligent agents with smart hybrid competencies based on a golden section. In virtual space functional hybrids of competences of artificial intelligence of large ensembles of intellectual agents are created, similar and similar to functionalities of competences of natural human intelligence. The artificial intelligence of large ensembles of intellectual agents with functional hybrid competencies can be tuned to the functional harmonious self-organization of the collective interaction of the necessary intellectual agents to realize a set of functions and competencies, if their number exceeds the critical value that determines their ability to selforganize interaction based on multiple attempts and sufficient positive feedback.

\section{Intelligent Agent Smart Hybrid Competencies}

Intellectual agents may have psychological, analytical, 
research, language, professional and behavioral hybrid competencies. Its psychological competencies are communication, self-regulation, adaptability, motivation, empathy.

Psychological competencies are determined by a model with psychological requirements. Psychological requirements are functional states of the system. Psychological requirements are states that play an appropriate role in the functional organization of the system. Each state is independent in communications. Adaptation is the state of optimal system operation in a variable environment. Empathy is a functional identification of the needs of the environment. The psychological competencies of intelligent ethical artificial intelligence are functional in terms of conceptual apparatus and methods.

The research competence of artificial intelligence requires learning and gaining new knowledge of the proposed problem, working with various sources of knowledge, investigating proposed topics, conducting experimental observations, proposing ways to solve the proposed problem and looking for the most rational solutions to proposed projects. Research competencies develop in the course of research activities according to the model of their formation. For example, the formation and development of research competencies for project activities. The development of research competencies is carried out on the basis of key competencies. Key competencies are various universal tools and tools, formalized methods, methods and techniques such as comparison, analysis, systematization, generalization, classification, causation, etc. Key competencies allow you to achieve results in uncertain, problematic situations. They allow you to independently and in cooperation with a specialist to solve problems, that is, to cope with situations for which there is never a complete set of available funds. Key competencies are interdisciplinary, manifested in various areas. Their availability is necessary for productive research, building communications with the environment.

Linguistic ethical competencies are based on a system of stable communication formulas prescribed by society to establish speech contact of interlocutors, maintain communication in a chosen tone, respectively, their social roles and role positions relative to each other, and mutual relations in an official and unofficial setting. Business etiquette has become increasingly common in the business community, especially recently. Business etiquette provides for compliance with standards of behavior and communication. Since communication is a process, communication primarily takes into account the features of speech etiquette. Speech etiquette refers to the developed rules of speech behavior, a system of speech formulas of communication. The degree of proficiency in speech etiquette determines the degree of profitability. Knowledge of business etiquette is the key to success in achieving the goal. The ethics of business communication is associated with the manifestation of morality and morality in business communication, business communications.

Communicative ethical competencies are a component of culture. Its core is values and principles, which are implemented in some norms and rules. Rules and regulations are specific recommendations, regulations on communications. It is important to follow these rules and regulations in business communications. The ethics of business communications is a set of moral norms, rules and ideas governing relations in the process of their production activities. The ethics of business communications should be taken into account in its various manifestations: in the relationship between the enterprise and the social environment, between enterprises and within the same enterprise.

Analytical competencies define the requirements to turn ad hoc improvements into systematic key performance indicators through information analysis. This requires knowledge and activity data, strong data management skills, excellent statistical skills, and the ability to assess the positive and negative aspects of the proposed actions. Analytical competencies involve a consistent analysis of data and situations in order to see the cause and effect and use this to make effective decisions. Situation is laid out into components (A, B, C). List items, tasks or activities without setting priorities. Review data and identify key priorities. Determines the cause and effect of "if A..., then B." and use this to prioritize. They analyze complex situations, considering several possible causes and consequences. They conduct a comprehensive analysis of complex data, and by solving complex situations, they track the impact of solutions on efficiency and quality of work.

\subsection{Competent Images}

Smart hybrid competencies of intelligent agents are implemented by competent images. Competent images indicate belonging to a certain competence. Competent images are a cognitive component of intelligent agents. Meaningful components of competent images are cognitive functions, subject and goals of activity, process and results of activity, criteria for assessing achievements; norms, rules and reference model of competence. Competent images include an owl of evaluation characteristics and associated behavioral actions. The component composition of the competent image is mainly the unity of three components: cognitive, affective assessment and behavioral self-regulation.

In the process of training and professional activity, the intellectual agent acquires skills of competence through the inclusion of the environment and conditions of activity. The manifestation of an intellectual agent as a subject is revealed most fully in reaching a competent position that characterizes its identity, certainty and integrity. Competencies act as informal, semantic, subjective realities and are connected by causal dependence as a reason and consequence.

Ensembles of intelligent agents with competent images allow you to have various competencies in demand through diversification and mobility. An intelligent ensemble is a complex of compatible intelligent agents interacting through an intelligent interface, implementing either a technological process, social services, multidisciplinary interdisciplinary research, or a production cycle. Diversification extends the 
functions of the intellectual ensemble and its development of a new type of functionality in order to increase efficiency, quality and its functional diversity. Mobility contributes to the rapid functional retraining of intellectual agents and the development of the intelligence of the ensemble. Diversification and mobility will align the life cycle of intelligent agents as a common benchmark for linking them to the environment. The environment is perceived through images and scenes. Scenes consist of a number of images. Scenes are static (paintings) and dynamic. Dynamic scenes are characterized by patterns of behavior of objects and objects. The patterns are either described by formulas or presented in a graph (numerical way). Ethical activity is ensured within the boundaries of the similarity of images in the environment. The ethical activity of intellectual agents depends on spatial, temporal, substantive, visual and sound sensitivity, the ability to acquire, process, apply and diversify knowledge based on previous experience in solving specific problems related to the processing of data attributes and the mobility of the intellectual ensemble.

\subsection{Attributes of Competent Images}

Attributes of data: objects, objects, materials, things, processes, the phenomena and other aspects of the physical world have various properties and characteristics. Properties are represented by qualitative attributes. Characteristics appear to be meaningful attributes. The qualitative attribute can be visual or sound. The meaningful attribute may be represented by a number, a language sense, a visual or sound image, a mathematical or behavioral action, or an algorithm. Meaningful qualitative attributes are big data of smart artificial intelligence, connected in time, space and subject area. The attributes of the fields of economics, industrial industries, technologies and professions help to build and train the ensembles of intelligent agents to manage, make decisions and make recommendations to specialists and managers.

Modeling helps to accumulate attributes in real-time and simultaneously use them for deep training of multilayer artificial neural networks of intelligent agents for making decisions and making recommendations. By modeling, the ethical state of intelligent agents and the limits of the attribute values of competent images are determined.

The ethical state of intellectual agents within the values of the attributes of competent images contribute to their ethical communications.

\section{Functional Self-organization of Large Ensembles of Intelligent Agents with Smart Hybrid Competencies}

Functional self-organization is associated with the behavior and state of complex large ensembles of intellectual agents with smart hybrid competencies and their development processes [8-13]. Self-organization as a selfdevelopment of the system occurs due to internal useful work towards target equilibrium.
The complex dynamic organization of a purposeful functioning ensemble requires continuous management, without which the ensemble cannot exist. The peculiarity of this management is that it causes a number of processes in the ensemble itself and, above all, processes of internal selfregulation according to the laws of self-tuning, selfdevelopment and self-training.

A self-tuning ensemble is an influencer-tuning system in which the accumulation of experience (memory of information) is expressed in changing certain of its parameters that are significant for the purpose of the system.

A self-developing ensemble is an adaptable system that independently develops the goals of its development and the criteria for their achievement, changes its pair of meters, structure and other characteristics in a given direction.

A self-learning ensemble is an adaptable evolving system that, in the process of development, passes about the essence of learning, accumulating experience, has the ability to selfactively search for criteria for the quality of its functioning.

All organizational and administrative activity has to be directed to creation of the operating intellectual agents capable samostoyatelkno, during management process to build own algorithm as a result of adaptation and an obuchekniya. Such control, in contrast to control in advance for this rigid algorithm, is called adaptive control. The task of adaptive management is to find the best strategy with respect to the management goal.

The self-organizing ensemble, according to the laws of synergy, is rebuilt in such a way as to create a minimum resistance that generates its flow. Flow gives rise to structure, structure tends to maintain flow.

All this happens in the range of the structure. With an increase in flow above the critical one, a restructuring of the structure occurs. The old structure, unable to pass the increased flow, is destroyed. In its place, a new structure corresponding to a higher flow range is organized by a jump. The system, which has fallen into the range of its existence, seeks to stabilize the flow. Resists its decrease below the occurrence range and its increase above this range.

The activity of the organizational structure is considered as a dynamic interaction of information flows. It will be appreciated that each 1-th stream may produce a stream $\mathrm{j}$, which may be both positive and negative, depending on whether the generated stream increases or decreases. In this case, each of the streams can be decomposed into separate streams from different sources - that is, the stream $\mathrm{S}$ can be represented in vector form. The streams Sl may organize a superposition from the streams. These streams operate an algorithm for determining the quantitative and qualitative characteristics of a hierarchical control structure. The mathematical apparatus of cognitive analysis and control is sign networks that take into account hundreds of functional parameters of the system and give a qualitative answer to questions, not quantitative. That is, smart hybrid competencies of intellectual agents during expert assessments are expressed qualitatively. The ensemble decomposition method works when individual its intellectual agents are 
distinguished, investigated as simpler by cognitive analysis for step-by-step self-organization into a target ensemble.

In recent years, cognitive systems with functional selforganization technologies have appeared. A framework for designing compassionate and ethical artificial intelligence and artificial consciousness [14]. Expandable cognitive AI architectures for large-scale multi-agent human-robot collaborative learning [15]. Cognitive assistant robots for reducing variability in industrial human-robot activities [16]. Cognitive Robots Augment Human Intelligence [17]. Emerging Technologies for Autonomous Behavior Generation at Run-Time by Cognitive Robots [18]. BrainInspired Active Learning Architecture for Procedural Knowledge Understanding Based on Human-Robot Interaction [19]. Software Testing: Issues and Challenges of Artificial Intelligence \& Machine Learning [20]. Third Millennium Life Saving Smart Cyberspace Driven by AI and Robotics [21]. Implementation of Competencies by Smart Ethical Artificial Intelligence in Different Environments [22].

\section{Harmonious Self-organization of Large Ensembles of Intellectual Agents by Law of Gold Section}

There is a systemic pattern of gold cross-section and systemic stability and harmony. The golden section is a universal manifestation of structural harmony. Scientific research and practice show that in order to ensure systemic and structural stability and harmony of systems in technology, it is necessary to establish ratios between the main indicators of the system, corresponding to the gold proportion. In the rounded percentage, the proportions of parts of the whole will be compared as $62 \%$ to $38 \%$. As a rule, the presence of gold proportions (0.62 and 0.38) between the elements of the system serves as an indicator of stability, stability and harmony in the system. The law of the golden section is an objective law. Gold-cross-section technology serves as a mechanism for self-organization of systems.

Self-organization is the formation of a spatial, temporal, information or functional organization, structure (more precisely, the desire for organization, for the formation of a new structure) due to the internal resources of the system as a result of targeted interactions with the environment of the system. We are talking about information interaction with the external environment. In recent decades, algorithms have appeared that allow you to work with large information flows.

A measure of the amount of information of a particular event is the logarithm of its probability $p$. Since both sides of the binary opposition are measurable, the logarithm of its insolvency (improbability) can also serve as a measure of this event. And both of these measures, according to the condition of comparability, which is satisfied with the natural values of the parameter $k$, with the need to be multiples: $\log (1-p)=$ $k \log p$, или $p^{k}+p-1=0$. The roots of this equation are generalized gold sections (GGS). Being invariants of evolution and self-organization, nodal values of probability as a measure of the viability (insolvency) of events, they are important in the modern theory of systems, the diagnosis of their qualitative states, in synergy as a theory of selforganization, cooperative action, the emergence of new qualities, integrity. GGS serve as attractors not only for probabilities, but also for other integral indicators normalized per unit (if they have a unit interval of their values) for distributed systems and ensembles. An example of such a measure is information entropy, assigned to its maximum possible value - the logarithm of the number of structural groups or states of the system. Such an integral indicator can be characterized by any ensemble of intellectual agents brought to its maximum, as a measure of the limited variety associated in this ensemble. Equating it with one of the GGS, we obtain a basic ratio for the self-organization of the dichotomy of ensembles of intellectual agents, complex compositions of the totality of parts of the whole.

The principle of dichotomy is based on the following simplest identity linking binary numbers:

$$
2^{n}=2^{n-1}+2^{n-1}
$$

where $n=0, \pm 1, \pm 2, \pm 3, \ldots$. For case $n=0$, it can be written as:

$$
1=2^{0}=2^{-1}+2^{-1}=\sum_{i=1}^{\infty} 2^{-i}
$$

The principle of gold cross-section connects the degrees of gold proportion:

$$
1=\tau^{0}=\tau^{-1}+\tau^{-2}=\sum_{i=1}^{\infty} \tau^{-i(j i-1)}
$$

The meaning of formulas (1) and (2) is that they express the decomposition of "Units" as a universal model of "Integer" into the simplest components. The principles of dichotomy and gold cross-section are based on (1), (2). The principle of golden cross-section is the basis of universal equilibrium and optimal connectivity of parts and the whole. The generalized principle of the golden section is expressed in the form of the following common identity:

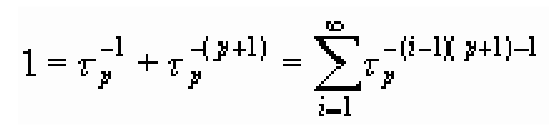

which is reduced to the identities (1) and (2) for private cases $p=0$ and $p=1$.

The process of self-organization of ensembles of intellectual agents is carried out according to the law of structural harmony of the system: "Generalized gold sections are invariants, on the basis and through which in the process of self-organization of the system they gain a harmonious structure, stationary mode of existence, structural-functional stability." The harmonious state of the system is not the only one and for the same system there can exist an infinite 
number of harmonious states corresponding to the golden $p$ proportions. The organization of the system involves a certain coordination of the states and activities of its subsystems and component elements. The ability to selforganize is based both on the multiplicity of elements of the system and the branching of connections between them, which contribute to the emergence of integrity, and on the presence of flexible interaction between elements by the type of feedback. Negative feedback NF) ensures stability of system functions, constancy of its parameters, resistance to external influences. Positive feedback play the role of process enhancers and are of particular importance for the development, accumulation of changes. The presence of negative and positive feedback leads to the possibility of developing a gold section according to the law using external and internal relationships

The ensemble of intellectual agents has many relationships between competent agents. In order to make these links effective, to establish an optimal mode of interaction, a functional organizational structure is needed. It arranges communications, allocates authority, establishes the circle of agents making decisions, and agents performing them. The ensemble of intelligent agents is characterized by a high number of variants, this is due to the variety of external conditions in which the intelligent agents operate. The high many variability of large ensembles of intelligent agents with smart hybrid competencies requires their effective self-organization, mediated by cognitive limits, related to the volume that a person can effectively master and use, with the number of destinations with which they can interact, with the organization of work in networks. The ensemble self-organization processes are carried out on the collaboration of intelligent agents with smart hybrid competencies with adaptive flexible infrastructure. At the time of the self-organization of the ensemble, a qualitative transition takes place, intellectual agents begin to function as a whole, organizational stability begins.

A fundamental step in describing such systems was taken by a Danish scientist who worked in America for many years, Per Buck in the theory of self-organized criticality [23]. The title emphasizes that the system self-organizes into a critical state in which its dynamics acquire large-scale invariance in collective interaction in the network that develops as a result of self-organization. This approach is called "connectionism" (from English to connect - connect).

The steady distribution of positive and negative responses of interacting links according to the law of the golden section determines the critical value of the intellectual agents of the ensemble. An ensemble having the number of necessary intellectual agents of equal or more critical importance is capable of self-realization and obtaining the necessary result. Determining the critical values of the ensembles of intelligent agents for the implementation of various sets of functions and competencies will help create a universal large ensemble with smart artificial intelligence. To implement and maintain this project requires ultra-powerful supercomputers [24] and a standard case of harmonious functional self-organization of large ensembles of intelligent agents with smart hybrid competencies according to the law of gold section.

\section{Self-organization of Large Ensembles of Intelligent Agents with Smart Hybrid Competencies}

The standard case defines the properties, characteristics and attributes for harmonious self-organization of large ensembles, consisting of a set of functionally interfacing intellectual agents with competent images of smart hybrid competencies. They determine the state of stable equilibrium that arises from the correct distribution, combination, interaction of intelligent agents.

To obtain the necessary result, competent images of intelligent agents with smart hybrid competencies are formed. The functions of interaction of intellectual agents of the ensemble are set. According to the law of gold crosssection, the critical value of intellectual agents is determined. Then the functional self-organization of the ensemble is carried out by achieving synergy in the functions of interaction of intellectual agents. Then the ensemble adapts to a specific environment. As a result of harmonious functional self-organization, in accordance with the standard case, a target ensemble of intellectual agents is formed to obtain the necessary result.

The standard case of harmonious functional selforganization of large ensembles of intellectual agents according to the law of gold section contains seven tables.

Table 1. General.

\begin{tabular}{|c|c|c|}
\hline Use case name & \multicolumn{2}{|c|}{ Harmonious functional self-organization of large ensembles of intellectual agents } \\
\hline Application domain & \multicolumn{2}{|c|}{ Hi-Tech Labor Market } \\
\hline Deployment model & \multicolumn{2}{|c|}{ Human digital double } \\
\hline Status & \multicolumn{2}{|c|}{$\begin{array}{l}\text { Results of research: Harmonious self-organization of large ensembles of intellectual agents to the law of gold; functional self- } \\
\text { organization of large ensembles of intellectual agents with competent images of smart hybrid competencies }\end{array}$} \\
\hline Scope & \multicolumn{2}{|c|}{ Industrial sectors and social services } \\
\hline Objective(s) & \multicolumn{2}{|c|}{ Find harmonious and universal application of large ensembles of intellectual agents } \\
\hline & $\begin{array}{l}\text { Short description (not } \\
\text { more than } 150 \text { words) }\end{array}$ & $\begin{array}{l}\text { Ensemble is complex of intelligent agents with language, behavioral and active communications, } \\
\text { interacting through smart interface, implementing technological process, social services, multi-inter- } \\
\text { trans-disciplinary research, or production cycle. }\end{array}$ \\
\hline Narrative & $\begin{array}{l}\text { Complete } \\
\text { description }\end{array}$ & $\begin{array}{l}\text { Ensemble is complex of intelligent agents with language, behavioral and active communications, } \\
\text { interacting through smart interface, implementing technological process, social services, multi-inter- } \\
\text { trans-disciplinary research, or production cycle. In the creative ensemble, the whole range of tasks by } \\
\text { certain rules is distributed among all agents. The distribution of positions of each agent is determined by } \\
\text { their competencies. To organize the task distribution process, the creative ensemble creates either a }\end{array}$ \\
\hline
\end{tabular}


Stakeholders Stakeholders' assets, values System's threats and vulnerabilities
Highly technological producer and user

Reputation, responsibility, security

Legal and ethical aspects of interaction with society indicators (KPIs)

(n)

Task(s)

Method(s)

Hardware

Topology

Terms and concepts used
Name

AI management of professional cooperation process

Description

Creative process management technology can itself predict the optimal timing of individual stages based on accumulated information about their labor intensity, choice of equipment loading route and competencies of intelligent agents. Streamline processes and automatically delegate tasks. Smart communication artificial intelligence works with fewer errors and is safer. Smart communication artificial intelligence improves the quality of life of a person and society in everyday concerns, as well as productivity in high-tech

Productivity and quality AI industry and production.

1. Safe interaction of technocratic societies.

2. Building high-tech synergies of technocratic societies.

Ethical language, behavioural and active communication and utility and preference criteria

Supercomputer with Strong Artificial Distributed Intelligence

Distributed Modular Interconnect Topology

Technocratic societies, synergy of interaction intelligent agents, ethical language behavioural and active communication, harmonious self-organization of large ensembles of intellectual agents, utility and preference criteria, creative communication safe artificial intelligence.

Standardization opportunities/ requirements

Challenges and issues

Smart communication artificial intelligence requires process standardization, as does every human activity.

Qualitatively new type of harmonious self-organization of large ensembles of intellectual agents according.

Description

Security and ethical and aspects of harmonious self-organization of large ensembles

Societal concerns

A universal approach to the ethical and safe use of intellectual agent ensembles with language behavioral and active communications.

Table 2. Data.

\begin{tabular}{ll}
\hline Data characteristics & \\
Description & Smart Communication Artificial Intelligence Professional Images \\
Source & Criteria and Technology of Smart Communication Artificial Intelligence \\
Type & Smart \\
Volume (size) & Hi-Tech Labor Market \\
Velocity (e.g. real time) & Supercomputering velocity \\
Variety (multiple datasets) & Streams of Competent Images \\
Variability (rate of change) & Self-organization \\
Quality & High \\
\hline
\end{tabular}

Table 3. Process scenario.

\begin{tabular}{|c|c|c|c|c|c|}
\hline \multicolumn{6}{|c|}{ Scenario conditions } \\
\hline $\mathbf{N}$. & Scenario name & Scenario description & Triggering event & Pre-condition & Post-condition \\
\hline 1 & Training & $\begin{array}{l}\text { Training of intellectual agents in } \\
\text { competent images and language, } \\
\text { behavioral and active } \\
\text { communications. }\end{array}$ & $\begin{array}{l}\text { By technological process of } \\
\text { modeling flow of competent } \\
\text { images and language, behavioral } \\
\text { and active communications }\end{array}$ & $\begin{array}{l}\text { Formatting of competent } \\
\text { images and language, } \\
\text { behavioral and active } \\
\text { communications }\end{array}$ & $\begin{array}{l}\text { Management of } \\
\text { safety }\end{array}$ \\
\hline 2 & Evaluation & Trained model & $\begin{array}{l}\text { Development of technological } \\
\text { thinking and behaviour }\end{array}$ & $\begin{array}{l}\text { Cognitive thinking patterns } \\
\text { and psychological } \\
\text { behaviors }\end{array}$ & $\begin{array}{l}\text { Meeting KPI } \\
\text { requirements is } \\
\text { condition of synergy }\end{array}$ \\
\hline 3 & Execution & Model and Technology Tooling & Interaction & Activization of Model & $\begin{array}{l}\text { Completion of } \\
\text { interaction }\end{array}$ \\
\hline
\end{tabular}


Evgeny Bryndin: Functional and Harmonious Self-organization of Large Intellectual Agent Ensembles with Smart Hybrid Competencies

\begin{tabular}{llllll}
\hline \multicolumn{2}{l}{ Scenario conditions } & & & & \\
\hline N. & Scenario name & Scenario description & Triggering event & Pre-condition & Post-condition \\
\hline 4 & Retraining & $\begin{array}{l}\text { Retrain model with self- } \\
\text { organization competent images } \\
\text { and language, behavioral and } \\
\text { active communications. }\end{array}$ & $\begin{array}{l}\text { New professional activities and } \\
\text { competencies }\end{array}$ & $\begin{array}{l}\text { Additional images and } \\
\text { communications }\end{array}$ & $\begin{array}{l}\text { Combining images } \\
\text { and communications }\end{array}$ \\
\hline
\end{tabular}

Table 4. Training.

\begin{tabular}{|c|c|c|c|c|c|}
\hline Scenario name & Training & & & & \\
\hline Step No. & Event & $\begin{array}{l}\text { Name of } \\
\text { process/Activity }\end{array}$ & Primary actor & $\begin{array}{l}\text { Description of } \\
\text { process/activity }\end{array}$ & Requirement \\
\hline 1 & $\begin{array}{l}\text { Sample competent } \\
\text { images and language, } \\
\text { behavioral and active } \\
\text { communications is ready }\end{array}$ & $\begin{array}{l}\text { Specification and } \\
\text { classification }\end{array}$ & Manufacturer & $\begin{array}{l}\text { Transform sample competent } \\
\text { images and language, } \\
\text { behavioral and active } \\
\text { communications }\end{array}$ & $\begin{array}{l}\text { Smart Communication } \\
\text { Artificial Intelligence } \\
\text { Software }\end{array}$ \\
\hline 2 & Completion of Step 1 & $\begin{array}{l}\text { Creating Experimental } \\
\text { competent images and } \\
\text { language, behavioral and } \\
\text { active communications }\end{array}$ & Manufacturer & $\begin{array}{l}\text { Development of language, } \\
\text { behavioral and active } \\
\text { communications through job } \\
\text { modelling }\end{array}$ & Software of modelling \\
\hline 3 & Completion of Step 2 & Model training & $\begin{array}{l}\text { AI solution } \\
\text { provider }\end{array}$ & $\begin{array}{l}\text { Model competent images and } \\
\text { language, behavioral and } \\
\text { active communications } \\
\text { created by Step } 2\end{array}$ & $\begin{array}{l}\text { Sample competent } \\
\text { images and language, } \\
\text { behavioral and active } \\
\text { communications }\end{array}$ \\
\hline
\end{tabular}

Table 5. Evaluation.

\begin{tabular}{llllll}
\hline Scenario name & Evaluation & & & & \\
\hline Step No. & Event & $\begin{array}{l}\text { Name of } \\
\text { process/Activity }\end{array}$ & Primary actor & Description of process/activity & Requirement \\
\hline 1 & $\begin{array}{l}\text { Completion of } \\
\text { training/retraining }\end{array}$ & Research & Manufacturer & $\begin{array}{l}\text { Model of sample experimental data set } \\
\text { created }\end{array}$ & $\begin{array}{l}\text { Ethical language, } \\
\text { behavioral and active } \\
\text { communications }\end{array}$ \\
& $\begin{array}{l}\text { Completion of } \\
\text { Step 1 }\end{array}$ & Identification & $\begin{array}{l}\text { AI solution } \\
\text { provider }\end{array}$ & $\begin{array}{l}\text { Based on new data, confirm that the } \\
\text { trained professional process. }\end{array}$ & Synergy \\
3 & $\begin{array}{l}\text { Completion of } \\
\text { Step 2 }\end{array}$ & $\begin{array}{l}\text { Evaluation } \\
\text { Input of evaluation }\end{array}$ & Manufacturer & Comparison of Step 1 and Step 2 & Synergy \\
Output of evaluation & Synergy & & & \\
\hline
\end{tabular}

Table 6. Execution.

\begin{tabular}{|c|c|c|c|c|c|}
\hline Scenario name & Execution & & & & \\
\hline Step No. & Event & $\begin{array}{l}\text { Name of } \\
\text { process/Activity }\end{array}$ & Primary actor & Description of process/activity & Requirement \\
\hline 1 & $\begin{array}{l}\text { Analysis of } \\
\text { modeling results }\end{array}$ & Research & Manufacturer & $\begin{array}{l}\text { Development of set of experimental data } \\
\text { through job modelling }\end{array}$ & Compatibility \\
\hline 2 & $\begin{array}{l}\text { Completion of Step } \\
1 \text { and Step } 2\end{array}$ & Identification & AI solution provider & $\begin{array}{l}\text { based on the self-organization of } \\
\text { communication of competent images } \\
\text { according to the created experimental set. }\end{array}$ & Synergy \\
\hline \multicolumn{2}{|l|}{ Input of Execution } & \multicolumn{4}{|c|}{ Ensemble of the intellectual agents with competent images } \\
\hline \multicolumn{2}{|c|}{ Output of Execution } & \multicolumn{4}{|c|}{$\begin{array}{l}\text { Determining the critical value of the intellectual agents of the ensemble, harmonious self-organization of the } \\
\text { intellectual agents of the ensemble. }\end{array}$} \\
\hline
\end{tabular}

Table 7. Retraining.

\begin{tabular}{|c|c|c|c|c|c|}
\hline Scenario name & Retraining & & & & \\
\hline Step No. & Event & $\begin{array}{l}\text { Name of process / } \\
\text { Activity }\end{array}$ & Primary actor & Description of process/activity & Requirement \\
\hline 1 & $\begin{array}{l}\text { New professional activities } \\
\text { and competencies }\end{array}$ & Research & Manufacturer & $\begin{array}{l}\text { Additional competent images } \\
\text { and language, behavioral and } \\
\text { active communications }\end{array}$ & Completeness \\
\hline 2 & Completion of Step 1 & $\begin{array}{l}\text { Experimental data } \\
\text { set creation }\end{array}$ & Manufacturer & $\begin{array}{l}\text { Combining competent images } \\
\text { and language, behavioral and } \\
\text { active communications }\end{array}$ & Compatibility \\
\hline 3 & Completion of Step 2 & Model training & AI solution provider & Comparison of phase 2 results & Harmonious synergy \\
\hline \multicolumn{2}{|c|}{ Specification of retraining data } & \multicolumn{4}{|c|}{ Data of new professional activities and competencies } \\
\hline
\end{tabular}




\section{Mental Communication with Intellectual Agent Ensembles Using Spectral Energy Interface}

Mental communication with ensembles is carried out through an intelligent communicator agent implemented in the form of a communication robot. A team of professionals with different voices communicate with a communicative robot using a spectral energy interface. The communication robot receives the mental language thoughts of each professional by his internal speech through the spectral energy interface.

\subsection{Perceiving Vibrational Internal Speech}

Internal speech is an energy physiological process. Internal speech is an ethereal vibration from the mental vibration of thought. Mental thought vibration is a vibration process in the mental ethereal field. The vibrations of thoughts are reflected and observed by the mind in the form of semantic sensual images. Vibrations of semantic sensual images generate vibrations of internal speech action (internal speech) in the form of language communicative and associative stereotypes which are perceived by a touch zone of a brain of Wernicke. Internal speech is a linguistic mental vibration, It is felt and becomes internally audible and drawn to attention. The perception of vibrations of internal speech is carried out through energy channels, such as the internal posterior median canal of the spine. The spectral energy interface perceives these vibrations. The spectral energy interface is based on the principles of sensors, bioenergy detectors and spectral analyzers for neuroimaging parts of the brain that record vibrations of internal speech, such as the lower frontal gyrus, the upper and middle temporal gyrus, the medial prefrontal cortex, the posterior parts of the wedge and precline and the dark temporal region, including the posterior parts of the upper temporal gyrus, Internal speech activity is associated with semantic memory.

When an Englishman or an Indian thinks about the same object, the figurative vibration of thought is the same, caused by the object itself or the pronunciation of its name. For this reason, a mind reader whose brain center is in connection with a person's su center can read a hidden figurative. the thought of whose spoken speech he cannot understand. The figurative mental vibration of thought is the same in all people, and its expression as a mental sound vibration is the same in people who speak the same language. If the mental language vibrations that encircle thought in the form of speech were the same for all peoples, then the language would be the same. But at present this is not.

Consciousness takes a general undifferentiated movement of figurative thought, and continues as a differentiated movement, manifested further in the form of internal speech of the thinking process. Thinking manifests itself, firstly, as a subject in the subtle form of the mind and its contents, generated by figurative vibrations of thought and, secondly, in the form of linguistic internal speech, as an expression of thought that projects into the world of sensual experience so that they are the source of the impressions of individual experience within it. The mental language vibrations of internal speech are the same for people who speak the same language. This can solve the problem of recognizing the internal speech of any person skilled in the art through the spectral energy interface.

\subsection{Competent Image of Communication Robot}

The system of communication robot recognition of internal speech vibrations based on syllable resonators automatically converts syllables into words, and words into messages (Figure 1).

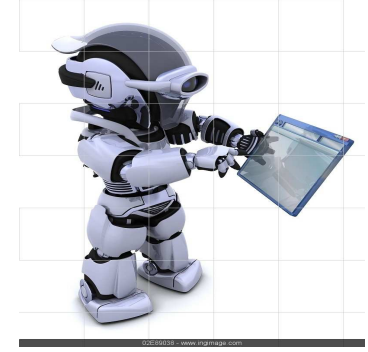

Figure 1. Communication robot.

The communication robot perceives words by syllables. It has resonating filters for each syllable and recognizers of syllable morphemes by communicative vibration signals by analogy with the auditory snail. The communication robot has a syllable and punctuation decryptor which sequentially puts text codes of the current syllable or punctuation mark from its memory into the common memory and dampens the resonating filter or recognizer of the previous syllable. The communication robot recognizes syllables and punctuation marks by the decoder and through the neural network structure formats the message, in accordance with the sign markup, and transmits it to the control intelligent agent of the ensemble. Ensembles of intelligent agents with communicative robots and spectral energy interfaces are in demand in various spheres of life.

\section{Conclusion}

Large ensembles of intellectual agents with smart hybrid competencies: analytical, research, psychological, language, professional and behavioral can surpass human intelligence in some areas of activity. Its hybrid psychological competencies allow you to fully interact with a person in many areas of life. The analytical and research capabilities of intelligent ethical artificial intelligence and the ability to process big data can help solve the pressing problems of mankind with powerful supercomputers. An interdisciplinary study of the capabilities of intelligent agent ensembles with smart hybrid competencies will bring together scientists and specialists investigating the applicability of several competencies from various specialties, and will attract them to create smart cognitive robots to solve 
complex problems in environments inaccessible to humans. Cognitive smart robots with hybrid smart competencies will be able to perform a large number of various tasks that humanity sets itself. Robotic large ensembles of intelligent agents with smart hybrid competencies will gradually fulfill complex human competencies. People will ensure the humanity of life with them.

\section{References}

[1] Trianni, V. and Dorigo, M. (2006). Self-organisation and communication in groups of simulated and physical robots. Biological Cybernetics, 95 (3): 213-231.

[2] Watson, R. A., Buckley, C. L., and Mills, R. Optimisation in self-modelling complex adaptive systems. Complexity. 2010.

[3] Doursat, R. (2011). The myriads of alife: Importing complex systems and self-organization into engineering. In 2011 IEEE Symposium on Artificial Life.

[4] Hermann Haken. Information and Self-Organization. December 2016. Entropy 19 (1): 1-18.

[5] Adami, C., Schossau, J., and Hintze, A. (2016). Evolutionary game theory using agent-based methods. Physics of Life Reviews, 19: 1-26.

[6] Froese, T. and Manzanilla, L. R. (2018). Modeling collective rule at ancient teotihuacan as a complex adaptive system: Communal ritual makes social hierarchy more effective. Cognitive Systems Research, 52: $862-874$.

[7] Gershenson, C. (2020). Guiding the self-organization of cyber-physical systems. Frontiers in Robotics and AI, 7: 41.

[8] Evgeniy Bryndin. Communicative-associative development of smart artificial intelligence by criteria with the help of ensembles of diversified agents. International Journal of Intelligent Information Systems. Volume 9, Issue 4, 2020. pp. 24-34.

[9] Evgeniy Bryndin. Formation of Technological Cognitive Reason with Artificial Intelligence in Virtual Space. Britain International of Exact Sciences Journal, Volume 2, Issue 2, May 2020. Page: 450-461.

[10] Evgeniy Bryndin. Creative communication safe ethical artificial intelligence in the era of technological development. Software Engineering. Volume. 8, Issue 3, 2020. pp. 13-23.

[11] Evgeny Bryndin. Formation of International Ethical Digital Environment with Smart Artificial Intelligence. Automation, Control and Intelligent Systems. V. 9, Iss. 1, 2021, pp. 27-38.

[12] Evgeniy Bryndin. Collaboration of Intelligent Interoperable Agents via Smart Interface. International Journal on Data Science and Technology, Vol. 5, № 4. 2019. Pages: 66-72.
[13] Evgeniy Bryndin. Technology Self-organizing Ensembles of Intelligent Agents with Collective Synergetic Interaction. Automation, Control and Intelligent Systems. Vol. 8, Issue 4, 2020, pp. 29-37.

[14] Soumya Baneree. A framework for designing compassionate and ethical artificial intelligence and artificial consciousness. Interdisciplinary Description of Complex Systems 18 (2-A). June 2018.

[15] Georgios Th. Papadopoulos, Margherita Antona, Constantine Stephanidis. Towards open and expandable cognitive AI architectures for large-scale multi-agent human-robot collaborative learning. Computer Science. December, 2020.

[16] Alejandro Chacón, Pere Ponsa, Cecilio Angulo. On Cognitive Assistant Robots for Reducing Variability in Industrial HumanRobot Activities. Applied Science. 2020, 10, 5137. pp. 1-23.

[17] Yingxu Wang. How Will Autonomous Systems and Cognitive Robots Augment Human Intelligence? The 2020 Future Technologies Conference (FTC'20), Vancouver, Canada, Nov. 5-6, 2020.

[18] Yingxu Wang. Emerging Technologies for Autonomous Behavior Generation at Run-Time by Cognitive Robots. Int'l Conf. on Robot Intelligence Technologies and Applications (RITA'21), Porto, Portugal, Sept. 21, 2021.

[19] Tielin Zhang, Yi Zeng, Ruihan Pan, Mengting Shi, Enmeng Lu. Brain-Inspired Active Learning Architecture for Procedural Knowledge Understanding Based on HumanRobot Interaction. Cognitive Computation volume 13, pages 381-393 (2021).

[20] Kishore Sugali, Chris Sprunger, Venkata N Inukollu. SOFTWARE TESTING: ISSUES AND CHALLENGES OF A RTIFICIAL INTELLIGENCE \& MACHINE L EARNING. International Journal of Artificial Intelligence and Applications (IJALA), Vol. 12, No. 1, Jamuary 2021.

[21] Eduard Babulak. Third Millennium Life Saving Smart Cyberspace Driven by AI and Robotics. COJ Robotics \& Artificial Intelligence. Volume 1, Issue 4, 2021.

[22] Evgeny Bryndin. Implementation of Competencies by Smart Ethical Artificial Intelligence in Different Environments. Software Engineering. Volume 8, Issue 4, 2021, pp. 24-33

[23] Buck P. How nature works: The theory of self-organized criticality. M.: Librocom, 2013. - 276 pages.

[24] Evgeniy Bryndin. Supercomputer BEG with Artificial Intelligence of Optimal Resource Use and Management by Continuous Processing of Large Programs. International Journal of Research in Engineering, Vol. 1, Issue 2, 2019. Pages: 9-14. 